\title{
Oficina de cirurgia cutânea: algumas considerações
}

\section{Cutaneous surgery workshop: some considerations}

Prezado Editor,

Lemos com grande interesse o artigo "Oficina de cirurgia cutânea. Rev Col Bras Cir. 2010;37(4):303-5". Parabenizamos a autora por esta contribuição ao ensino-aprendizagem das bases da cirurgia, ao mesmo tempo em que fazemos algumas perguntas e considerações:

1. Partindo-se do princípio de que as habilidades cirúrgicas básicas não são adquiridas por uma grande porcentagem de acadêmicos e são extremamente relevantes para a formação do médico generalista', por qual motivo a oficina é apenas opcional/complementar ao âmbito curricular?

2. Recentemente apresentamos um modelo sintético confeccionado com etileno vinil acetato (EVA) para a aprendizagem das habilidades cirúrgicas básicas². $\mathrm{Na}$ RCBC, foram descritos simuladores não biológico ${ }^{3} \mathrm{e}$ biológico (língua bovina) ${ }^{4} \mathrm{Com}$ propósitos semelhantes. Os modelos animais post-mortem (peles de porco e galinha e língua bovina) parecem oferecer maior similaridade aos tecidos humanos quando comparados com os materiais sintéticos. No entanto, a fidelidade do material não é tão importante ${ }^{5}$ e, adicionalmente existe evidência de que a transferência de competências de iniciantes na prática cirúrgica para o ambiente clínico é semelhante quando são obtidas quer seja a partir de modelos baratos de baixa fidelidade ou de simuladores de alta fidelidade ${ }^{6}$. Dessa forma, quais seriam os benefícios da pata de porco, quando comparada com outros simuladores (sintéticos e biológicos)?

3. Ao passo que Dubrowski e cols. ${ }^{7}$ demonstraram que um instrutor para cada quatro alunos é a proporção ideal para o ensino das habilidades de sutura para estudantes de medicina ${ }^{7}$, qual seria o número de instrutores a ser utilizado na oficina ( 18 instrutores para atender 60 estudantes ou um instrutor para cada grupo com seis estudantes)?

4. Tendo em vista que a retenção e transferência de habilidades cirúrgicas são mais robustas quando adquiridas de uma maneira intercalada com períodos de descanso, ao invés do ensino em um único tempo e, que a retenção da habilidade, ao contrário do nível de habilidade imediatamente após o treinamento, deve ser o objetivo final de qualquer $\mathrm{CursO}^{8}$, por que especificamente quatro horas de treinamento? Adotamos ${ }^{2}$ o ensino-aprendizagem na sala de técnica operatória e em casa com um feedback imediato e posterior do professor/instrutor, respectivamente. Após a prática em casa, o acadêmico traz o modelo com suturas e retalhos efetuados para que fatores como profundidade da penetração na "pele", espaçamento dos pontos, eversão da "pele" e coaptação das bordas sejam avaliados e ensinados novamente ao aluno. Para este treinamento em momentos diferentes, o simulador deve ser acessível, reprodutível, reutilizável, de baixo custo financeiro e fácil manuseio, como, por exemplo, o modelo de $\mathrm{EVA}^{2}$, diferentemente do animal post-mortem, que requer espaço e condições adequadas para ser armazenado, conforme é relatado pela autora.

5. Acreditamos que seria interessante estabelecer critérios que mensurem o aprendizado do aluno. Assim sendo, a validação de um teste para quantificar as habilidades técnicas aprendidas poderia ser utilizado como uma ferramenta de certificação ${ }^{9}$. Desta maneira, quais seriam os critérios de mensuração da aprendizagem utilizados na avaliação aplicada?

Agradecemos a autora pela contribuição e principalmente pela preocupação com a formação dos novos médicos. Acreditamos que os princípios da cirurgia devem ser consolidados durante o período de graduação. Portanto, colocamos nossos esforços para o desenvolvimento de um modelo de ensino que contemple as necessidades dos alunos de nosso país.

\section{Rafael Denadai Pigozzi Silva Érika Malheiros Bastos}

\section{REFERENCIAS}

1. Birch DW, Mavis B. A needs assessment study of undergraduate surgical education. Can J Surg. 2006;49(5):335-40.

2. Bastos EM, Silva RDP. Proposal of a synthetic ethylene-vinyl acetate bench model for surgical foundations learning. Suture training. Acta Cir Bras. 2011;26(2):149-152.

3. Ebram Neto J, Cauduro AB, Speranzini MB. Dispositivo para o treinamento e avaliação das habilidades em técnica operatória. Rev Col Bras Cir. 1998;25(5):354-6.

4. Franco D, Medeiros J, Grossi A, Franco T. Uso de língua bovina na prática de técnicas de sutura. Rev Col Bras Cir. 2008;35(6):442-4.

5. Reznick RK, MacRae H. Teaching surgical skills-changes in the wind. N Engl J Med. 2006;355(25):2664-9.

6. Grober ED, Hamstra SJ, Wanzel KR, Reznick RK, Matsumoto ED, Sidhu RS, Jarvi KA. The educational impact of bench model fidelity on the acquisition of technical skill: the use of clinically relevant outcome measures. Ann Surg. 2004;240(2):374-81

7. Dubrowski A, MacRae H. Randomised, controlled study investigating the optimal instructor: student ratios for teaching suturing skills. Med Educ. 2006;40(1):59-63.

8. Moulton CA, Dubrowski A, Macrae H, Graham B, Grober E, Reznick R. Teaching surgical skills: what kind of practice makes perfect?: a randomized, controlled trial. Ann Surg. 2006:244(3):400-9

9. Reznick R, Regehr G, MacRae H, Martin J, McCulloch W. Testing technical skill via an innovative "bench station" examination. Am J Surg. 1997;173(3):226-30. 


\section{Resposta da Carta ao Editor}

\section{Oficina de cirurgia cutânea: algumas considerações}

\section{Cutaneous surgery workshop: some considerations}

\author{
Prezado Editor,
}

Em relação às perguntas e considerações referentes ao artigo "Oficina de cirurgia cutânea. Rev Col Bras Cir. 2010;37(4):303-5", que me foram enviadas na data de hoje 15/08/2011 pela revista, tenho as seguintes colocações:

1. Partindo-se do princípio de que as habilidades cirúrgicas básicas não são adquiridas por uma grande porcentagem de acadêmicos e são extremamente relevantes para a formação do médico generalista ${ }^{1}$, por qual motivo a oficina é apenas opcional/complementar ao âmbito curricular?

Esta proposta de oficina foi elaborada na disciplina de dermatologia, pela qual sou responsável, como contribuiçã̃o ao treinamento cirúrgico cutâneo dos alunos. Entretanto, como se trata de uma disciplina com ênfase clinica para alunos do $3^{\circ}$ ano e com carga horária restrita de $45 \mathrm{~h}$ não foi possível sua operacionalização. A proposta foi realizada na disciplina de cirurgia ambulatorial para alunos do $4^{\circ}$ ano, onde também leciono, mas sua incorporação ao curso de medicina depende de uma série de fatores que fogem do meu alcance.

2. Recentemente apresentamos um modelo sintético confeccionado com etileno vinil acetato (EVA) para a aprendizagem das habilidades cirúrgicas básicas ${ }^{2}$. $\mathrm{Na}$ $\mathrm{RCBC}$, foram descritos simuladores não biológico ${ }^{3}$ e biológico (língua bovina) ${ }^{4}$ com propósitos semelhantes. Os modelos animais post-mortem (peles de porco e galinha e língua bovina) parecem oferecer maior similaridade aos tecidos humanos quando comparados com os materiais sintéticos. No entanto, a fidelidade do material não é tão importante ${ }^{5}$ e, adicionalmente existe evidência de que a transferência de competências de iniciantes na prática cirúrgica para o ambiente clínico é semelhante quando são obtidas quer seja a partir de modelos baratos de baixa fidelidade ou de simuladores de alta fidelidade ${ }^{6}$. Dessa forma, quais seriam os benefícios da pata de porco, quando comparada com outros simuladores (sintéticos e biológicos)?

Ela complementou os demais treinamentos previstos no currículo. Sua vantagem é que os porcos já estavam disponíveis para a programação de cirurgia experimental e aproveitamos as patas que seriam descartadas para realizar a oficina cutânea sem custos adicionais, agregando outros benefícios diretos aos alunos.

Tivemos oportunidade de apresentar esta opção da pata de porco no Congresso Brasileiro de Educação
Médica, realizado em Curitiba em 2009, no painel de métodos alternativos de ensino de cirurgia com ótima receptividade. Além disto, tenho recebido contatos no meu e-mail, disponibilizado no artigo em questão, e a troca de experiências têm sido muito saudável e enriquecedora.

3. Ao passo que Dubrowski e cols. ${ }^{7}$ demonstraram que um instrutor para cada quatro alunos é a proporção ideal para o ensino das habilidades de sutura para estudantes de medicina 7 , qual seria o número de instrutores a ser utilizado na oficina (18 instrutores para atender 60 estudantes ou um instrutor para cada grupo com seis estudantes)?

Pode ser um professor para cada mesa cirúrgica composta por seis alunos. Como temos acadêmicos monitores nas disciplinas de dermatologia e cirurgia eles também foram treinados para oferecer suporte na reposição de material, auxiliar professores e estudantes na realização dos exercícios propostos, bem como, receber noções de organização de eventos técnico-científicos.

4. Tendo em vista que a retenção e transferência de habilidades cirúrgicas são mais robustas quando adquiridas de uma maneira intercalada com períodos de descanso, ao invés do ensino em um único tempo e, que a retenção da habilidade, ao contrário do nível de habilidade imediatamente após o treinamento, deve ser o objetivo final de qualquer curso $^{8}$, por que especificamente quatro horas de treinamento? Adotamos ${ }^{2}$ o ensino-aprendizagem na sala de técnica operatória e em casa com um feedback imediato e posterior do professor/instrutor, respectivamente. Após a prática em casa, o acadêmico traz o modelo com suturas e retalhos efetuados para que fatores como profundidade da penetração na "pele", espaçamento dos pontos, eversão da "pele" e coaptação das bordas sejam avaliados e ensinados novamente ao aluno. Para este treinamento em momentos diferentes, o simulador deve ser acessível, reprodutível, reutilizável, de baixo custo financeiro e fácil manuseio, como, por exemplo, o modelo de $\mathrm{EVA}^{2}$, diferentemente do animal post-mortem, que requer espaço e condições adequadas para ser armazenado, conforme é relatado pela autora.

Para conseguir reunir todos os professores, monitores e alunos otimizamos o tempo realizando a oficina durante um período de quatro horas (manhã ou tarde) com um intervalo. Além disso, na prática médica, ocorrem cirurgias demoradas que requerem disciplina, determinação e preparo físico para a sua realização e entendemos que isto também faz parte do treinamento. Observamos que este tipo de workshop possibilita boa interação e facilita o esclarecimento imediato de dúvidas. Quanto ao espaço físico, o centro cirúrgico experimental possui condições adequadas e excelente estrutura.

5. Acreditamos que seria interessante estabelecer critérios que mensurem o aprendizado do aluno. Assim sendo, a validação de um teste para quantificar as habilidades técnicas aprendidas poderia ser utilizado como uma ferramenta de certificação ${ }^{9}$. Desta maneira, quais seriam os critérios de mensuração da aprendizagem utilizados na avaliação aplicada? 
Entre os critérios empregamos: 1) método repetitivo-reprodutivo 2), avaliação dos professores, dos pares da mesa cirúrgica e do próprio estudante quanto ao domínio do ensino-aprendizagem, 3) questionário antes e depois. Estes alunos continuaram o treinamento durante o semestre na disciplina de cirurgia ambulatorial, através de aulas teóricas, teórico-práticas e práticas. Pudemos verificar que houve incorporação de técnicas ensinadas e que a abordagem metodológica da oficina, apesar das limitações, mostrou-se produtiva.

Esta oficina foi integrada ao programa do CIPLAST (Curso Interuniversitário Anual de Cirurgia Plástica, realizado pela PUC PR). Em conjunto com outros colegas cirurgiões e dermatologistas temos realizado oficinas semelhantes e estamos conscientes que muitos detalhes precisam ser aperfeiçoados.
Temos convicção de que esta pequena parcela de contribuição ao ensino tem feito diferença para os alunos que participam deste treinamento. Um artigo apresentando os resultados obtidos em uma das oficinas foi elaborado e encaminhado recentemente para submissão a RCBC.

Espero ter respondido aos questionamentos e agradeço a gentileza do contato. As observações e sugestões do autor da carta vão contribuir para o melhoramento deste trabalho. Coloco-me a disposição para qualquer esclarecimento adicional.

Dra. Kátia Sheylla Malta Purim _ CRMPR 10363 Professora das Disciplinas de Dermatologia e Cirurgia Ambulatorial Universidade Positivo - Curitiba- Paraná E-mail: katiasheylla@up.com.br 